\title{
Increased Spot Urinary Protein-to-Creatinine Ratio Can Be a Useful Predictor of Preeclampsia
}

\author{
Mai Nishimura, Ayaka Nakashima, Takuya Kushimoto, Mayako Goto, Susumu Yoshida, \\ Osamu Sato, Kayoko Shikado, Kazuhide Ogita \\ Department of Obstetrics \& Gynecology, Rinku General Medical Center, Osaka, Japan \\ Email: MaiNQQ119@gmail.com
}

Received 21 October 2015; accepted 26 November 2015; published 1 December 2015

Copyright (C) 2015 by authors and Scientific Research Publishing Inc.

This work is licensed under the Creative Commons Attribution International License (CC BY). http://creativecommons.org/licenses/by/4.0/

(c) (i) Open Access

\section{Abstract}

Objectives: Preeclampsia is a major cause of maternal and perinatal morbidity and mortality. Early diagnosis of preeclampsia is important to help patients with preeclampsia. However, 24-hour urine collection is the gold standard diagnostic method at present. Recently, the spot urinary protein-to-creatinine ratio ( $\mathrm{P} / \mathrm{C}$ ratio) has been used to detect suspected preeclampsia, because it can be used to estimate the amount of 24-hour urinary protein. The aim of this study is to investigate whether an increase in $\mathrm{P} / \mathrm{C}$ ratio precedes emergence of hypertension among inpatients with preeclampsia. Method: The $\mathrm{P} / \mathrm{C}$ ratio in normotensive (systolic blood pressure $<140 \mathrm{~mm} \mathrm{Hg}$ and diastolic blood pressure $<90 \mathrm{~mm} \mathrm{Hg}$ ) pregnant women was measured during regular prenatal checkups and in inpatients with preeclampsia between April 1, 2013 and March 31, 2014. Results: We included in this study 4074 normotensive pregnant women. The 95 th percentile values for the trimester of pregnancy were $0.100,0.157$, and 0.195 , respectively. The 95 th percentile value for each trimester of pregnancy and gestational age were determined as criterion ( $Y$ ) and predictive variables $(\mathrm{X})$, respectively. In a simple regression analysis, the regression line was calculated as $\mathrm{Y}$ $=0.0035 X+0.0849\left(R^{2}=0.9913\right)$. Twenty-one women were diagnosed with preeclampsia. In 14 patients with preeclampsia, the timing of the increase in $\mathrm{P} / \mathrm{C}$ ratio to higher than the regression line preceded the emergence of hypertension. Six patients had no data on $P / C$ ratio, and 1 patient had hypertension before the increase in $\mathrm{P} / \mathrm{C}$ ratio. Conclusions: An increase in $\mathrm{P} / \mathrm{C}$ ratio to higher than the 95th percentile value can be a useful predictor of preeclampsia.

\section{Keywords}

Preeclampsia, Eclampsia, Protein-to-Creatinine Ratio, Pregnancy Induced Hypertension, Proteinuria

How to cite this paper: Nishimura, M., Nakashima, A., Kushimoto, T., Goto, M., Yoshida, S., Sato, O., Shikado, K. and Ogita, K. (2015) Increased Spot Urinary Protein-to-Creatinine Ratio Can Be a Useful Predictor of Preeclampsia. Open Journal of Obstetrics and Gynecology, 5, 808-812. http://dx.doi.org/10.4236/ojog.2015.514114 


\section{Introduction}

Hypertensive diseases complicate 5\% - 10\% of all pregnancies [1]. The World Health Organization reported that $16 \%$ of maternal deaths in developed countries were the result of hypertensive disorders. Urinary dipstick testing and blood pressure measurement during routine prenatal visits are important for the early detection of preeclampsia, which can help pregnant women avoid critical hypertensive complications.

Urinary dipstick test results are influenced by many factors, so the actual amount of urinary protein varies widely [2]. The spot urinary protein-to-creatinine ratio (P/C ratio) is a known estimate of 24-hour urinary protein and is simpler to perform. Recently, it has been used to detect suspected preeclampsia, although the 24-hour urine collection method remains the gold standard. In Japan, the United Kingdom and Australia, the P/C ratio is recommended for use as a substitute for 24-hour urinary protein.

We have often observed that formerly normotensive pregnant women appear to exhibit hypertension after the emergence of proteinuria in our daily practice and in the literature [3]. We hypothesize that increased $\mathrm{P} / \mathrm{C}$ ratio precedes the emergence of hypertension in patients with finally diagnosed preeclampsia and eclampsia. The purpose of this study is to determine the variations in the $\mathrm{P} / \mathrm{C}$ ratio in normotensive pregnant women and to determine whether increase in $\mathrm{P} / \mathrm{C}$ ratio precedes the emergence of hypertension in patients with preeclampsia.

\section{Materials and Methods}

This was a retrospective observational study. In a pilot study, we obtained the P/C ratio and urinary dipstick test results of normotensive (systolic blood pressure < $140 \mathrm{~mm} \mathrm{Hg}$ and diastolic blood pressure $<90 \mathrm{~mm} \mathrm{Hg}$ ) Japanese pregnant outpatients undergoing regular prenatal checkups between April 1, 2013 and March 31, 2014. Patients with multiple gestation and known past medical history of renal disease were excluded. Urinary protein and creatinine levels were measured in milligram per deciliter. We calculated the 95th percentile value for each trimester of pregnancy. The 95th percentile value for each trimester of pregnancy and gestational age were determined as criterion (Y) and predictive variables (X), respectively, and a simple regression line was calculated.

In the main study, we investigated whether an increase in $\mathrm{P} / \mathrm{C}$ ratio to higher than the 95th percentile simple regression line preceded the emergence of hypertension among patients with preeclampsia and eclampsia. Hypertension was defined as a systolic blood pressure $\geq 140 \mathrm{~mm} \mathrm{Hg}$ or a diastolic blood pressure $\geq 90 \mathrm{~mm} \mathrm{Hg}$ applied to the report of the American College of Obstetricians and Gynecologists' Task Force on Hypertension in Pregnancy [4]. We defined a clinically significant increase in $\mathrm{P} / \mathrm{C}$ ratio as an increase in $\mathrm{P} / \mathrm{C}$ ratio to higher than the 95th percentile simple regression line.

This study was approved by the institutional review board of Rinku General Medical Center. The authors have no conflicts of interest to declare. Informed consent was obtained from participants.

\section{Results}

In the pilot study, there were a cumulative total of 4074 women who met our inclusion criteria. All women were Japanese. The median values of systolic and diastolic blood pressure were $111 \mathrm{~mm} \mathrm{Hg}$ and $66 \mathrm{~mm} \mathrm{Hg}$, respectively. The median value of gestational age was 31 weeks of gestation. The median values for the P/C ratio in each trimester of pregnancy were 0.045, 0.060, and 0.076, respectively (Figure 1, Table 1). The 95 percentile value in each trimester was $0.100,0.157$ and 0.195 respectively. The 95 percentile value in each trimester and the gestational age were determined as criterion variable $(\mathrm{Y})$ and predictor variable $(\mathrm{X})$ respectively. In simple regression, a regression line was calculated as $\mathrm{Y}=0.0035 \mathrm{X}+0.0849\left(\mathrm{R}^{2}=0.9913\right)$. The 95 percentile value of $\mathrm{P} / \mathrm{C}$ ratio slightly increased between 0.1549 and 0.2319 according to the gestational age (20 - 42 weeks of gestation).

In the main study, 15 patients were met our criteria. All patients were tested 24-hour urine collection. A clinically significant increase in $\mathrm{P} / \mathrm{C}$ ratio was preceded by hypertension in only 1 woman who was diagnosed superimposed preeclampsia. Hypertension was preceded by a clinically significant increase in P/C ratio in 14 women (Table 2). Between 14 women, 2 (14.3\%) women were twin pregnancy and 12 (85.7\%) women were single pregnancy. 9 women (64.3\%) were primigravida and 5 women (35.7\%) were multigravida. No women had placental abruption. The urine dipstick results when the $\mathrm{P} / \mathrm{C}$ ratio exceeded 95 percentile value were as follows: were 2 (14.3\%), \pm were 4 (28.6\%), 1+ were 3 (21.4\%), 2+ were 2 (14.3\%), 3+ were $3(21.4 \%)$. P/C ratio exceeded the 95 percentile value within 24 hours in 7 women (50.0\%) and more than 24 hours in the remaining 7 women (50.0\%). 


\section{Discussion}

The 24-hour urine collection is the traditional method for directly determining total daily protein excretion. Although there are many options for diagnosing proteinuria, daily protein excretion as determined by 24-hour urine collection is considered to be the gold standard for quantifying proteinuria during pregnancy.

There are some disadvantages in 24-hour urine collection. It is time-consuming, but moreover, there is a fear that the 24-hour urine collection is a frequently inaccurate and imprecise measure of proteinuria [5] [6]. Côté et al. retrospectively investigated the completeness of 24-hour urine collection. They found that especially lean body weight was more likely to lead to an inaccurate result. Thus, when interpreting the results of a 24-hour urine collection, it is critical to assess the adequacy of collection by also quantifying the 24-hour urine creatinine excretion, which is based on muscle mass. The 24-hour urine creatinine excretion should be between 15 and 20 $\mathrm{mg} / \mathrm{kg}$ body weight, calculated by using pre-pregnancy body weight.

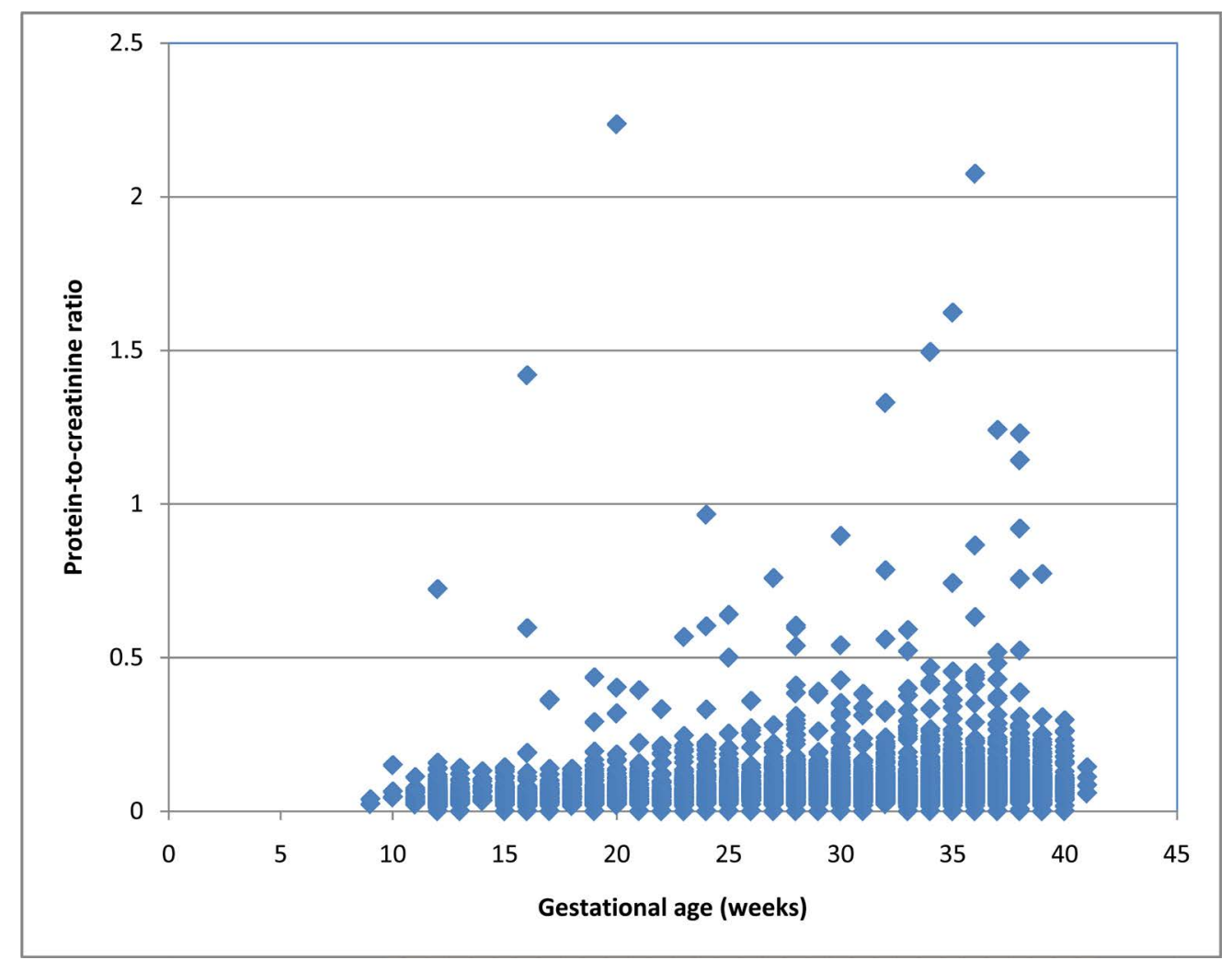

The protein: creatinine ratio and gestational age were determined as the criterion $(\mathrm{Y})$ and predictor $(\mathrm{X})$ variables, respectively. This figure indicates that the protein-to-creatinine ratio was almost unchanged during pregnancy.

Figure 1. Relationship between the $\mathrm{P} / \mathrm{C}$ ratio and gestational age.

Table 1. Median and the 95th percentile values for the P/C ratio in each trimester of pregnancy.

\begin{tabular}{cccc}
\hline & Median & Range & 95th percentile \\
\hline Systolic Blood Pressure (mm Hg) & 111 & $66-139$ & 130 \\
Diastolic Blood Pressure (mm Hg) & 66 & $31-89$ & 79 \\
Gestational Age (weeks) & 31 & $9-41$ & 0.196 \\
P/C ratio & 0.07 & $0-2.236$ & 0.100 \\
P/C ratio in 1st trimester ( $=236)$ & 0.045 & $0-0.723$ & 0.157 \\
P/C ratio in 2nd trimester ( $=1353)$ & 0.060 & $0-2.236$ & 0.195 \\
P/C ratio in 3rd trimester ( $=2485)$ & 0.076 & $0-2.075$ & \\
\hline
\end{tabular}

P/C ratio: Protein-to-creatinine ratio. 
Table 2. The characteristics of the patients with isolated proteinuria and subsequent pregnancy.

\begin{tabular}{ccccccccc}
\hline Pt & Gestational age (weeks) & Age (y/o) & G & P & Delivery & Dipstick results & FGR & Final diagnosis \\
\hline 1 & $37+3$ & 35 & 1 & 0 & VD & - & - & Severe PE \\
2 & $37+4$ & 24 & 2 & 1 & VD & - & - & Mild PE \\
3 & $39+0$ & 30 & 1 & 0 & VD & \pm & - & Severe PE \\
4 & $38+6$ & 31 & 1 & 0 & VD & \pm & - & Mild PE \\
5 & $39+3$ & 41 & 2 & 1 & VD & \pm & - & Severe PE \\
6 & $35+1$ & 28 & 3 & 0 & CS & \pm & + & Severe PE, twin \\
7 & $37+4$ & 23 & 2 & 0 & VD & $1+$ & - & Mild PE \\
8 & $35+2$ & 37 & 4 & 1 & CS & $1+$ & - & Severe PE \\
9 & $32+4$ & 37 & 1 & 0 & VD & $1+$ & + & Severe PE \\
10 & $34+4$ & 40 & 6 & 5 & VD & $2+$ & + & Eclampsia \\
11 & $35+5$ & 32 & 1 & 0 & VD & $2+$ & LFD & Severe PE, Severe proteinuria \\
12 & $33+4$ & 31 & 1 & 0 & CS & $3+$ & - & Severe PE \\
13 & $34+6$ & 26 & 3 & 0 & CS & $3+$ & - & Mild PE, twin \\
14 & $30+2$ & 39 & 2 & 1 & CS & $3+$ & - & Severe PE, Severe proteinuria \\
\hline
\end{tabular}

Pt: patient, y/o: year-old, G: gravida, P: para, VD: vaginal delivery, CS: cesarean section, FGR: fetal growth retardation, LFD: large-for-date, PE: preeclampsia.

The $\mathrm{P} / \mathrm{C}$ ratio is an alternative for assessing proteinuria in pregnancy and has become the preferred method. It is highly correlated with the amount of 24-hour urinary protein excreted by women with suspected preeclampsia [7] [8]. Some systematic reviews have suggested that a P/C ratio above $0.7 \mathrm{mg}$ is strongly correlated with significant proteinuria. On the other hand, the optimal value of the $\mathrm{P} / \mathrm{C}$ ratio that effectively excludes proteinuria above $300 \mathrm{mg} / \mathrm{day}$ has ranged between 0.13 - 0.26 in various studies [5] [9] [10]. In our study, the 95 percentile value of P/C ratio varies from 0.1549 to 0.2319 according to the gestational age (20 - 42 weeks of gestation). The results are comparable to the previous reports [5] [9] [10], therefore, it is considered that P/C ratio above this 95 percentile value simple regression line is useful for diagnosing preeclampsia.

The definite diagnosis of proteinuria without hypertension in pregnancy, so-called "gestational proteinuria", must wait until 12 weeks postpartum, because gestational proteinuria is defined as transient proteinuria (more than $0.3 \mathrm{~g} /$ day) between 20 weeks of gestation and 12 weeks postpartum. Morikawa et al. reported that the women who developed proteinuria in the absence of hypertension after 20 weeks of gestation was more likely to progress to preeclampsia than women who exhibited new hypertension in the absence of proteinuria (51\% vs. $15 \%, \mathrm{p}=0.002$ ) [3]. Moreover, Morikawa et al. reported preterm birth and fetal growth restriction were more common in women with initially isolated proteinuria. On the other hand, the outcome of gestational proteinuria is reported that it is similar to the healthy women [11] [12]. Thus, in practice, we must pay attention to women with proteinuria in the absence of hypertension, because they are at risk of subsequent preeclampsia. These previous evidence support our main study result that women with initially isolated proteinuria in pregnancy and subsequent hypertension were at risk of preeclampsia and poor maternal and neonatal outcome.

Our study has several limitations. First, this study was retrospective, so the timing of test P/C ratio was not regular. Second, this was a single-center study. A prospective randomized multi-center study including women from several ethnicities is needed for more precise assessment of the normal upper limit of $\mathrm{P} / \mathrm{C}$ ratio as a predictor of preeclampsia/eclampsia and poor maternal and neonatal outcome.

In spite of these limitations, the strength of our study is that it is the first study to quantify the normal upper limit of $\mathrm{P} / \mathrm{C}$ ratio and use it as a predictor of preeclampsia/eclampsia. We propose that a $\mathrm{P} / \mathrm{C}$ ratio above the 95th percentile should be followed with confirmatory testing with a 24-hour urine collection to diagnose preeclampsia/eclampsia.

\section{References}

[1] Cunningham, G. (2014) Hypertensive Disorders, Williams Obstetrics. 24th Edition, McGraw-Hill, New York

[2] Lamb, E.J., MacKenzie, F. and Stevens, P.E. (2009) How Should Proteinuria Be Detected and Measured? Annals of 
Clinical Biochemistry, 46, 205-217. http://dx.doi.org/10.1258/acb.2009.009007

[3] Yamada, T., Yamada, T., Morikawa, M., Takeda, M., Nishida, R., Akaishi, R. and Minakami, H. (2011) Isolated Proteinuria as an Initial Sign of Severe Preeclampsia. Open Journal of Obstetrics and Gynecology, 1, 13-16. http://dx.doi.org/10.4236/ojog.2011.12003

[4] The American College of Obstetricians and Gynecologists’ Task Force on Hypertension in Pregnancy (2013) Hypertension in Pregnancy. Obstetrics \& Gynecology, 122, 1122-1131.

[5] Morris, R.K., Riley, R.D., Doug, M., Deeks, J.J. and Kilby, M.D. (2012) Diagnostic Accuracy of Spot Urinary Protein and Albumin to Creatinine Ratios for Detection of Significant Proteinuria or Adverse Pregnancy Outcome in Patients with Suspected Preeclampsia: Systematic Review and Meta-Analysis. BMJ, 345, e4342-e4353. http://dx.doi.org/10.1136/bmj.e4342

[6] Côté, A.M., Firoz, T., Mattman, A., Lam, E.M., von Dadelszen, P. and Magee, L.A. (2008) The 24-Hour Urine Collection: Gold Standard or Historical Practice? American Journal of Obstetrics \& Gynecology, 199, 625e1-625e6.

[7] Robert, M., Sepandj, F., Liston, R.M. and Dooley, K.C. (1997) Random Protein-Creatinine Ratio for the Quantitation of Proteinuria in Pregnancy. Obstetrics \& Gynecology, 90, 893-895. http://dx.doi.org/10.1016/S0029-7844(97)00536-X

[8] Neithardt, A.B., Dooley, S.L. and Borensztajn, J. (2002) Prediction of 24-Hour Protein Excretion in Pregnancy with a Single Voided Urine Protein-to-Creatinine Ratio. American Journal of Obstetrics \& Gynecology, 186, 883-886. http://dx.doi.org/10.1067/mob.2002.123055

[9] Côté, A.M., Brown, M.A., Lam, E., von Dadelszen, P., Firoz, T., Liston, R.M. and Magee, L.A. (2008) Diagnostic Accuracy of Urinary Spot Protein: Creatinine Ratio for Proteinuria in Hypertensive Pregnant Women: Systematic Review. BMJ, 336, 1003-1006. http://dx.doi.org/10.1136/bmj.39532.543947.BE

[10] Papanna, R., Mann, L.K., Kouides, R.W. and Glantz, J.C. (2008) Protein/Creatinine Ratio in Preeclampsia: A Systematic Review. Obstetrics \& Gynecology, 112, 135-144. http://dx.doi.org/10.1097/AOG.0b013e3181778cfc

[11] Morikawa, M., Yamada, T., Yamada, T., Cho, K., Yamada, H., Sakuragi, N. and Minakami, H. (2008) Pregnancy Outcome of Women who Developed Proteinuria in the Absence of Hypertension after Mid-Gestation. Journal of Perinatal Medicine, 36, 419-424. http://dx.doi.org/10.1515/JPM.2008.062

[12] Holston, A.M., Qian, C., Yu, K.F., Epstein, F.H., Karumanchi, S.A. and Levine, R.J. (2009) Circulating Angiogenic Factors in Gestational Proteinuria without Hypertension. American Journal of Obstetrics \& Gynecology, 200, 392.e1392.e10. http://dx.doi.org/10.1016/j.ajog.2008.10.033 